Journal of School and University Medicine, Vol VIII, Issue 4, October - December 2021

\title{
VISION SCREENING OF FOUR-AND FIVE-YEAR-OLD CHILDREN IN CLUJ COUNTY: RECOMMENDATIONS FOR NATIONWIDE IMPLEMENTATION
}

\author{
Jan Kik ${ }^{1}$, Mandy Nordmann ${ }^{1}$, Daniela Rajka', Mihai Mara², \\ Simona Cainap, Oana Teodosescu², Alin Vladescu3, Aurel Mocan ${ }^{3}$, \\ Anna Horwood ${ }^{4}$, Maria Fronius ${ }^{5}$, Cristina Vladutiu ${ }^{2}$, Huibert Jan Simonsz ${ }^{1}$ \\ ${ }^{1}$ Erasmus University Medical Center, Department of Ophthalmology, Rotterdam, the Netherlands \\ ${ }^{2}$ University of Medicine and Pharmacy, Cluj-Napoca, Romania \\ ${ }^{3}$ Department of Social and Medical Assistance, Cluj-Napoca, Romania \\ ${ }^{4}$ University of Reading, School of Psychology and Clinical Language Sciences, Reading, United \\ Kingdom \\ ${ }^{5}$ Goethe University, Department of Ophthalmology, Child Vision Research Unit, Frankfurt am Main,
}

Germany

\section{Abstract}

BACKGROUND: Vision screening by measurement of visual acuity at age four or five was implemented in Cluj County in 2018 and 2019. Our aim was to identify barriers and facilitators to implementation and to formulate conditions for nationwide implementation of vision screening in Romania.

METHODS: In cities, children were screened by resident kindergarten nurses. In rural areas, kindergartens are small and have no nurses. Children were screened by family doctors' nurses instead, initially at the doctors' offices and later also at kindergartens. Because rural coverage was low in the first year, a travelling screening nurse was employed to screen children in remote rural areas.

Implementation was assessed with on-site observations, interviews, questionnaires and analysis of screening results, including ophthalmological examinations.
RESULTS: In cities, $74.8 \%$ of eligible children were screened, in rural areas, $47.1 \%$. The travelling screening nurse screened 805 children in seven months and rural communes where screening had taken place increased from 24 to 72 out of 75 during the second year. Referral rate was $15.8 \%$ initially, decreasing to $7.9 \%$, varying between $0 \%$ and $57.1 \%$ among screeners. Of referred children, $27.8 \%$ were reported back by ophthalmologists, $15.3 \%$ were examined but not reported back, $21.4 \%$ were not examined and of $35.4 \%$ it was unclear whether they were examined. Referral and treatment were hampered by travel distance and lack of awareness. Of children reported back by ophthalmologists, $34.1 \%$ were prescribed glasses, $7.2 \%$ both glasses and occlusion and $0.7 \%$ occlusion. Vision screening was considered acceptable by respondents. However, in rural communes screening was deemed less appropriate and feasible. Fidelity was high in both urban and rural areas.

* Corresponding author: Huibert Jan Simonsz, e-mail: simonsz@compuserve.com, Erasmus University Medical Center, Department of Ophthalmology, Rotterdam, the Netherlands

Article received: 01.11 .2021 , accepted: 16.11 .2021 , published: 15.12 .2021

Cite: Kik J, Nordmann M, Rajka D, Mara M, Cainap S, Teodosescu O, Vladescu A Mocan A, Horwood A, Fronius M, Vladutiu C, Simonsz HJ. Vision screening of four- and five-year-old children in cluj county: recommendations for nationwide implementation. The Journal of School and University Medicine. 2021;VIII(4): 5-23 
CONCLUSIONS: In cities, screening by kindergarten nurses proved very effective. In rural areas, family doctors' nurses screened only screen small numbers of children. The travelling screening nurse screened many children in underserved rural communes and screening had been offered in almost all rural communes at the end of the study. Universal vision screening at age four or five in Romania will result in many children with amblyopia needing treatment with glasses and eye patches, for which reimbursement by health insurance may be necessary. A training programme for orthoptists to assist ophthalmologists could be advisable.

KEY WORDS: vision screening, amblyopia, children, implementation study, disparity

\section{BACKGROUND}

The EUSCREEN Study [1] aimed to make vision and hearing screening available for all children in Europe by comparing current screening programmes in Europe and by developing an online cost-effectiveness model [2] to assist with the introduction of a screening programme, taking into account the local circumstances in any given country. In Romania, few children are screened for vision. Family doctors have the option to screen for vision disorders every year from age two to age seventeen, as part of a general screening examination of children that also includes many other tests such as weight, length and skull measurements, neuro-psychological-emotional development and dental development [3]. If all these tests are performed, the general screening examination is awarded 5.5 points by the health insurance. It is unknown how often these examinations are performed, but it is likely many family doctors lack the time for these examinations. These screening examinations take more time than other examinations, such as checks of patients with hypertension or diabetes, that are awarded 6 points.

A vision screening programme was implemented in Cluj County (see Additional file 1 for demographics) with the aim of identifying requisites, facilitators, and barriers for screening. The implementation started on January $1^{\text {st }}, 2018$ and ended on December 31 st 2019.
We have reported previously on the first year of implementation of vision screening in Cluj County [4] and found considerable differences between vision screening in urban and screening in rural areas.

Considering that in Romania $46 \%$ of the population lives in rural areas [5], this disparity between urban and rural areas could be an obstacle to nationwide implementation of paediatric vision screening.

Amblyopia, a lazy eye, has a prevalence of approximately $3.4 \%$ [6] and is the main target condition for paediatric vision screening.

It is the most common cause of visual impairment in young children [7]. It can only be detected by measurement of visual acuity and treated quickly and effectively until age six [8]. The measurement of visual acuity at age four or five is extremely important, because it detects amblyopia in almost all cases and is considered effective to reduce the prevalence of persistent amblyopia [9]. Vision screening by measurement of visual acuity is common in most countries in Europe.

Vision screening by measurement of visual acuity at age four or five was implemented in Cluj County in 2018 and 2019. Here we report on the implementation of screening, the results of screening and referrals and make recommendations for nationwide implementation of universal vision screening in Romania.

\section{METHODS Screening population}

The target population was defined as children aged four and five, because they are old enough for visual acuity measurement [10] and young enough to be successfully treated for amblyopia if needed [7]. Screening was performed from January 1st, 2018 until December $31^{\text {st }}, 2019$. Hence, all children born in Cluj in 2013, 2014 and 2015 were eligible.

A new protocol for measurement of visual acuity at age four or five was developed, to a large extent in accordance with the ISO standard 8596 [11], but using logarithmically ordered Tumbling E and LEA Symbols, with a three metre test distance. The protocol is described in detail in Additional file 2 and the protocol itself can be found as Additional file 3 . 


\section{Screening personnel and training}

In the county seat Cluj-Napoca and five small cities (Turda, Dej, Câmpia Turzii, Gherla and the town of Huedin), kindergartens have resident nurses. These were trained to screen, because they were allowed to do so because of their medical training.

In rural kindergartens there generally are no resident nurses because most rural kindergartens are small and kindergartens need at least 60 children to have a nurse [12]. Kindergartens have teachers who are qualified education professionals. In rural areas recruiting qualified staff can be difficult [13]. Because kindergarten teachers do not have a medical background they are not allowed to screen children. It was therefore decided that the children in rural communes would be screened by the family doctors or their nurses at the family doctor's office.

A training programme for nurses and doctors was developed and supervised by one of the authors (CV). All nurses who screened children received $€ 7$,gross (around $€ 4$,- net) per child screened in addition to their salary.

Towards the end of the first year of implementation children had been screened in 24 out of 75 rural communes. Therefore, after eight months, some family doctors' nurses began to screen children in rural kindergartens rather than the doctor's office, but this proved insufficient to improve rural coverage substantially.

\section{Travelling screening nurse}

To facilitate screening in rural communes where no screening had taken place in the first year, a travelling screening nurse was employed three months into the second year of implementation, to visit these communes as a dedicated screener. The travelling screening nurse first visited a kindergarten to explain the screening and to hand out consent forms for the parents. This was necessary because screening took place in the context of a study. She kept in touch with the kindergarten teachers by phone and once the consent forms were signed, visited the kindergarten again to screen the children. The travelling screening nurse had to use her own car to visit the rural kindergartens and only her fuel was reimbursed. Other expenses such as meals were not because of labour regulations in force [14].

The travelling screening nurse was initially paid €7,- per child screened. In September 2019 this amount was raised to $€ 10$ to cover use of a personal car and to make it worthwhile to visit the most remote and thinly populated communes.

\section{Information for parents and children and referral}

Parents were informed about the purpose of screening with leaflets and posters that explained the study in lay terminology. Children were informed of the screening procedure with an educational cartoon [15]. In adherence to the Declaration of Helsinki [16], parents' informed consent was obtained before screening. They had to sign a consent form, approved by the UMF-Cluj's Ethics Committee.

If the child did not pass the screening, a second screening could be scheduled if the screener had the impression the child failed because of a lack of attention instead of actual low vision. In other cases, the parents were instructed to visit their family doctor for referral to an ophthalmologist. After the ophthalmological examination, the ophthalmologist was supposed to fill out a form with the results. The parents were to return this form to the screener. If the child had been screened by the travelling screening nurse, they were supposed to return the form to the kindergarten.

\section{Implementation assessment}

The implementation outcomes that were assessed, based on the work of Peters et al. [17] and Proctor et al. [18], were acceptability, feasibility, appropriateness, adoption, fidelity, coverage and sustainability. The implementation was assessed with mixed methods: on-site observations, interviews, questionnaires and analysis of screening and examination results.

Four visits were made to Romania by several of the authors for on-site interviews and observations during the implementation: in January 2018 (HJS, 
MN), March 2018 (HJS, MN), January 2019 (MF, $\mathrm{AH}, \mathrm{MN}, \mathrm{JK}$ ) and October 2019 (MN, JK). Screening locations throughout the county were visited, where screening nurses, family doctors, kindergarten staff, supporting staff and public servants were interviewed. The interviews were semi-structured [19]. Different interview guides were prepared for different professionals. Reports were made of the interviews by two of the authors (MN, JK). These reports were subjected to inductive analysis, as described by Thomas [20].

Screenings were observed by one of the authors $(\mathrm{MN})$. The explanation and screening test duration were measured with a stopwatch. It was observed whether screening was performed in accordance with the protocol. During the on-site visits in the second year of implementation, mostly rural locations were visited, to investigate the causes that impeded the implementation of screening in rural areas.

A questionnaire was developed for screeners and distributed during the on-site visits in March 2018 and January and October 2019. After four months of implementation, a questionnaire was sent to 98 out of 115 rural family doctors, to gain insight into the difficulties they faced that prevented them or their nurses from performing vision screening.

Eight months after conclusion of the screening, the screeners were asked by email if they could provide information on whether children, who had been referred but for whom no ophthalmological examination report had been received, were examined or not.

An electronic database (see Additional file 2 for description) was developed for data analysis. Project secretaries in Cluj-Napoca entered the data on the screening of all children. This included the outcome of the screening as well as the results of the diagnostic examination by the ophthalmologist. The database was used to monitor screening results and follow-up activity.

The data in the database met the requirements of EU regulation 2016/679 (GDPR). Each child was assigned a code and all personally identifying information (including place of residence) was omitted.

All screening and examination data were exported from the electronic database on October 17, 2020 for analysis. The data were analysed, using Microsoft Excel 2016 (version 16.0.5188.1000).

\section{Results \\ Screening personnel and training}

Courses for screeners were held in 2017 and 2018 and were attended by 233 persons (154 nurses and 79 doctors). To be allowed to screen they had to pass a certifying test. From the cities, 103 nurses attended the course, $73(70.9 \%)$ of whom went on to screen children. From the rural areas, 51 nurses followed the course, $30(58.8 \%)$ of whom went on to screen children. The average number of children screened during the two years of the implementation by one kindergarten nurse in the cities was 130 (median 122), and that by one family doctors' nurse in rural areas was 79 (median 46).

\section{Screening coverage}

In 2018 and 2019, 12,866 children were screened, or $1.95 \mathrm{x}$ the average birth rate ( 3 birth years were eligible over the two-year period). In the cities $2.24 \mathrm{x}$ the average birth rate was screened and in the rural areas $1.41 \mathrm{x}$.

In the cities, most children were screened in the first year of the implementation (70.3\%), while in the rural areas, most children were screened in the second year (66.4\%; figure 1$)$.

Most of the family doctors' nurses in rural areas who screened children at the doctor's office, reported in the interviews that this was often unsuccessful because, when parents were invited specifically for screening, the majority did not come. In the focus groups of nurses, it was said that the parents did not have time to come and it did not seem a priority for them. A lack of awareness of the benefits of preventive healthcare was also noted.

In September 2018, family doctors' nurses were advised to start screening children at the kindergartens instead of the doctors' offices. Two nurses had already begun doing this of their own accord. The nurses in the focus groups were positive about this way of screening, with the exception of one nurse who encountered a lack of cooperation on the part of the kindergarten staff and two nurses who said there was no suitable space to screen at the kindergarten. 
Figure 1: children screened per quarter in cities and in rural areas

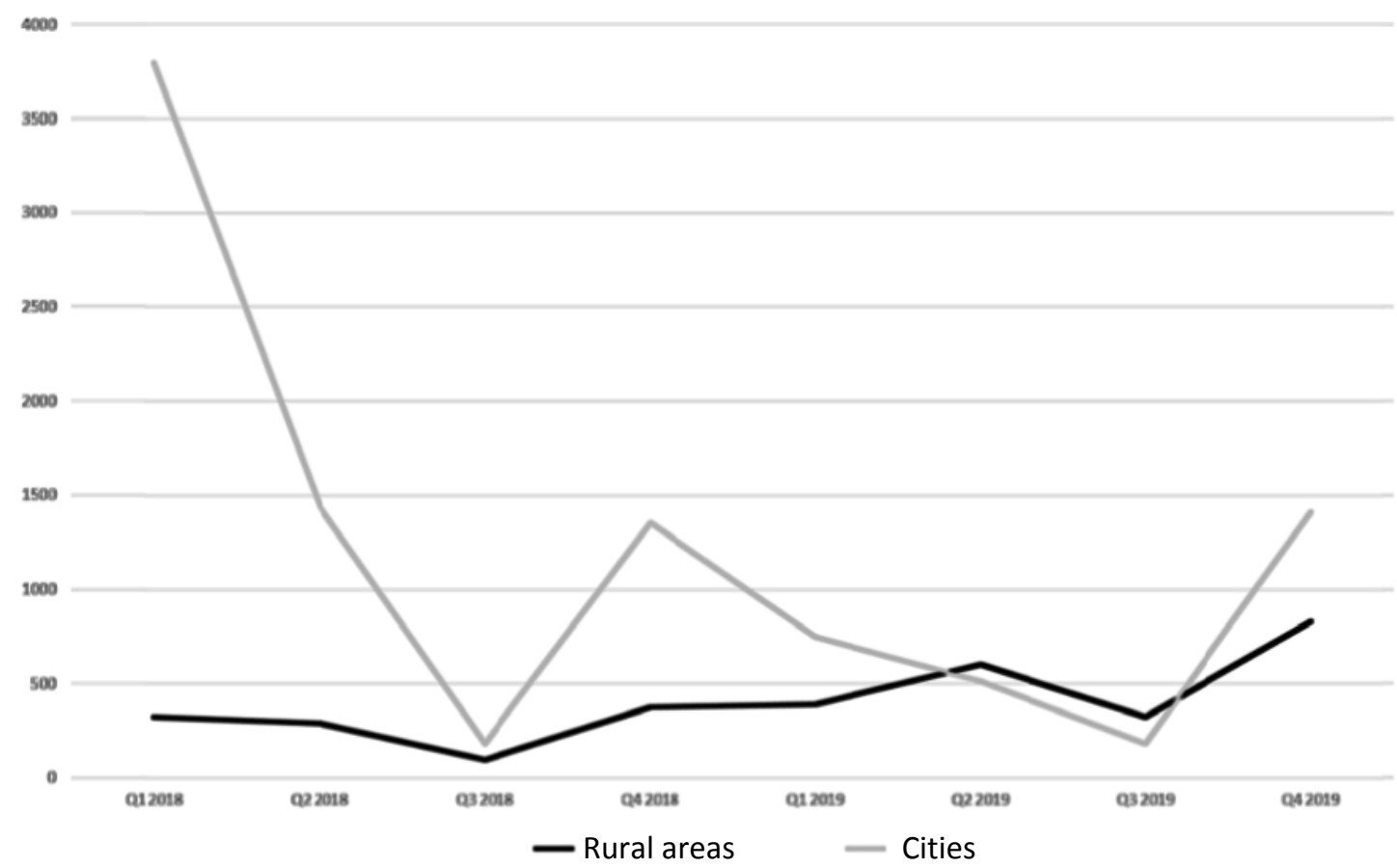

Some parents refused consent. Exactly how many is not known, because this was not recorded. Nurses (both individually and in the focus groups) and kindergarten teachers gave different accounts: most said all parents consented without any trouble or only a few refused, while some reported more parents refused. There were notable differences between locations, although there did not appear to be an urban-rural divide when it came to consent. Nurses and kindergarten teachers mentioned several reasons why parents refused: they did not want to fill out their identification number (cod numeric personal) on the consent form, they were afraid to sign something, the child had already been diagnosed with an eye condition and they did not consider screening important. One nurse mentioned it was difficult to get the parents to consent: it just seemed not a priority for them and they did not take the trouble to fill out the consent form, did not return it or forgot about it.

\section{Travelling screening nurse}

The employment of a travelling screening nurse in March 2019 increased coverage in the rural areas substantially. At the end of 2018 children had been screened in only 24 of 75 rural communes. At the end of 2019 this had increased to 72 . In 32 of these, children were screened only by the travelling screening nurse. She screened 805 children between March and October 2019, against 1,346 children who were screened by 25 family doctors' nurses in the whole year.

In the communes where children were only screened by the travelling screening nurse, on average 22 children were screened. In the communes where children were only screened by family doctors' nurses, on average 38 children were screened. This illustrates that the travelling screening nurse screened children in less populated communes.

The travelling screening nurse needed a lot of travelling time to screen children, not only because she first had to deliver consent forms and many villages were far from Cluj-Napoca but also because in many rural kindergartens the number of eligible children was small. Moreover, children expected to be in the kindergartens were often absent. According to kindergarten teachers, this was because many parents who work in nearby cities take their children to the kindergartens there and because many parents who go abroad to work, take their children with them.

According to the travelling screening nurse herself, her job required a lot of effort per child screened. 
She had to visit each kindergarten at least twice because informed consent forms were needed for the study (note that consent forms will not be needed during regular screening in the future). In some cases, she had to visit a kindergarten a third time, because on the first visit many children were absent. To collect the reports of the ophthalmological examinations, in principle she had to visit kindergartens a third or fourth time.

Finally, she mentioned the uncertainty about the number of children she would be able to screen, implying that she had no stable income. She had to use her own car. Her travelling expenses, other than fuel, were not reimbursed, like car damage caused by poor road conditions.

\section{Referral to family doctor and ophthalmologist}

A total of 1,505 children was referred (11.7\%). There were large differences between screeners though, with referral rates varying from $0 \%$ to $57.1 \%$. Referral rates decreased as screeners gained experience, from $15.8 \%$ in the first quarter of 2018 to $7.9 \%$ in the last quarter of 2019.

Out of 103 screeners, 30 had a referral rate higher than $15 \%$ and 34 had a referral rate below 5\%.

Thirteen of the latter, who together screened 692 children (5.4\%), did not refer a single child. Two of these screened more than 92 children. This is highly implausible: assuming a prevalence of amblyopia of $3.2 \%$, the chance of not referring any children is less than $5 \%$ as soon as the number of examined children exceeds 92, according to the formula (HP Prime) BINOMIAL_CDF $(93,0.032,0)=0.0486$, which is slightly less than alpha $=0.05$. Another nurse screened 86 children in 2018 and recorded exactly the same visual acuity for all of them in both eyes, according to the database.

Figure 2: flow chart of eligible children in 2018 and 2019.

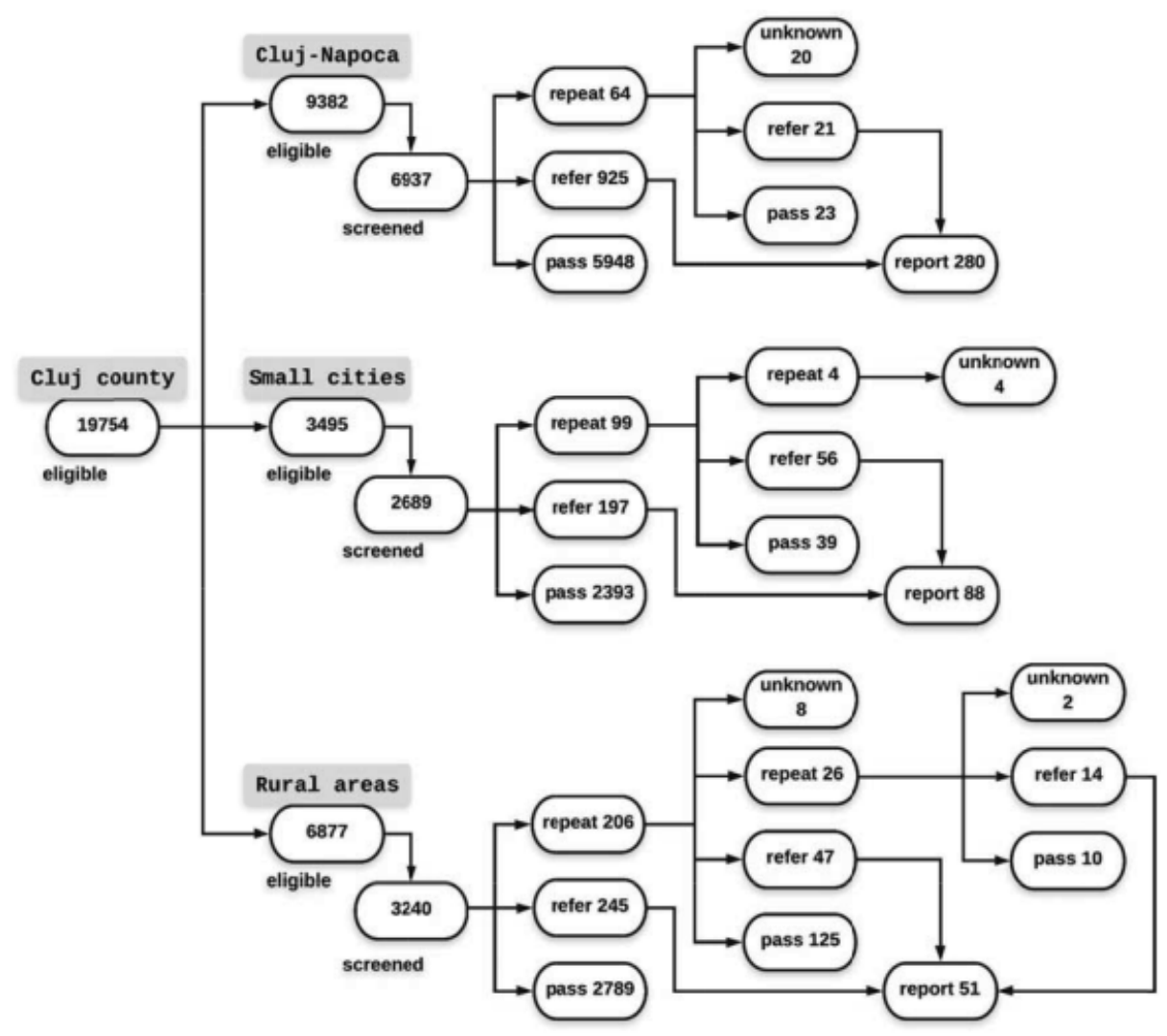

Note: Eligible children were children born in 2013, 2014 and 2015. 'Refer' denotes referral to an ophthalmologist, 'report' denotes a report was returned by the ophthalmologist to the screener 
It was decided that children screened by nurses who had no referrals and had screened more than 92 children, would be examined again by ophthalmologists who participated in the study. In the first two months of 2020, 91 of these 799 children were examined again, of whom eight $(8.8 \%)$ were found to have a visual acuity different from the initial measurement by the screening nurse. Further re-examinations, however, were not possible because of the Covid-19 pandemic.

Ophthalmologists returned 419 (27.8\%) examination reports, mostly handed by the parents back to the screening nurse: about $30.7 \%$ of referred children screened in cities, about $22.6 \%$ of referred children screened in rural areas by family doctors' nurses and about $5.6 \%$ of referred children screened by the travelling screening nurse. The latter low percentage was caused by the fact that it was very difficult for the travelling screening nurse to return to all the kindergartens where she screened children, in 35 different communes throughout the county, to collect examination reports.

A flow chart of the screening and referral process is presented in figure 2. Of the 419 children for whom a report was entered in the database, $34.1 \%$ were prescribed glasses, $7.2 \%$ were prescribed a combination of glasses and occlusion therapy and $0.7 \%$ were prescribed occlusion therapy. The remaining $58.0 \%$ were not prescribed treatment.
Nurses who had referred children for whom no diagnostic report was received, were asked by email if they could contact the parents of these children to ask whether these children had been examined by an ophthalmologist.

Out of $1,086(72.2 \%)$ children referred for whom no report was received, in 231 cases $(15.3 \%)$ the nurses reported the child had been examined by an ophthalmologist, but the result had not been received. According to some nurses, some ophthalmologists refused to fill out the form because they considered it too much trouble. According to several nurses (both individually and in the focus groups) and kindergarten teachers, it also happened that the ophthalmologist filled out the form, but the parents never returned it, especially if there was nothing wrong with the child.

In 322 cases $(21.4 \%)$ the child was, as far as the nurses could tell, not examined despite being referred. Reasons given were similar to the reasons in the interviews, such as parents' lack of interest or understanding of the importance or that the parents could not be contacted anymore.

In 533 cases (35.4\%) the nurses could not say whether the child had been examined, because they had been unable to contact the parents. In the focus groups, it was mentioned that some children left the kindergarten shortly after being screened, because of which the teachers no longer were in contact with the parents and never received the form.

Figure 3: referred children examined by ophthalmologist and reports of examinations received from ophthalmologists

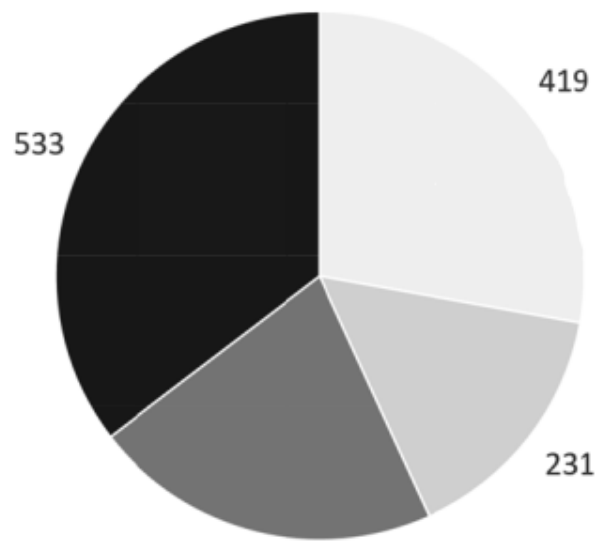

322

Examined, report in database

Not examined

Examined, no report in database

- Unknown 
According to the information provided by the nurses, at least $43.2 \%$ of referred children were examined (figure 3). Assuming that of the unknown cases also $43.2 \%$ were examined, $58.0 \%$ of all referred children would have been examined.

Nurses' and teachers' opinions differed on whether parents would take their children to an ophthalmologist. Some said most or all parents would do so, but others said most or all parents would not do so, or about half the parents would do so. It was mentioned several times that this would depend on the parents' affluence, because poor parents could not afford to. There are no ophthalmologists in rural areas so travel to a city was necessary: either to a small city nearby, or, if there were no ophthalmologists there able and willing to examine children, to the county seat ClujNapoca. The costs of treatment were reported to be a problem as well for poor parents. It was mentioned by several nurses and kindergarten staff that only offering screening does not suffice and glasses and occlusion patches for the treatment of amblyopia should be reimbursed as well.

Several other barriers to follow-up were mentioned by nurses and teachers, such as that parents had to go to the family doctor for a referral. Some parents lacked awareness, especially in rural areas, and did not see the importance of following up a failed screening test. Some parents were reported to have other priorities and/or a lack of time. Some parents were said to refuse to accept their child had a problem because as far as they could tell the child could see and they could not observe that something was wrong.

\section{Performance of the screeners}

A total of 16 screenings were observed in ClujNapoca (5), the small cities (8) and rural areas (3) by one of the authors (MN) in October 2019. The observations indicated that most nurses' screening performance was satisfactory and had improved as compared to earlier observations [4]. The average time a screening test took was around five minutes, compared to 8:20 minutes when screening had just commenced.

The nurses instructed the children well and seemed comfortable in performing the screening. Not all nurses were fully aware of the referral criteria (refer when there is a difference of two or more $\log$ MAR lines in visual acuity between both eyes or when visual acuity is 0.5 or less for a four-year-old or 0.63 or less for a five-year-old), but the nurses knew that the measurement of visual acuity had to continue after the monocular threshold for referral had been reached.

It was observed that screening in rural areas, at the doctor's office by the nurse, took a lot of time and effort. Because the child was not used to the nurse and in an unfamiliar setting, screening was difficult, even though a parent was present. Other than this, no noteworthy differences were observed between screenings in rural and urban areas.

\section{Assessment of the implementation}

In January 2019, 34 people were interviewed: thirteen family doctors, fourteen nurses and seven kindergarten staff. In October 2019, a total of 62 people were interviewed. There were two focus groups with nurses: one with six nurses from Cluj-Napoca and one with twelve nurses from throughout the county. The other 44 people were interviewed individually or in pairs (for example two staff members at the same kindergarten). These were thirteen kindergarten staff, eleven kindergarten nurses, six supporting staff (legal and financial advisors, project secretaries), five family doctors' nurses, three family doctors, three public servants, two ophthalmologists and the travelling screening nurse. The questionnaire for screeners was answered by altogether 49 screeners and the questionnaire for rural family doctors was answered by 23 family doctors.

We assessed the acceptability, feasibility, appropriateness, adoption, fidelity, coverage and sustainability of the implemented screening programme. A schematic overview of all the assessed implementation outcomes, in relation to the measurement methods used, is presented in tables 1a-g.

Vision screening was considered acceptable (table 1a): all stakeholders felt it was important and expressed a positive attitude towards it. 'Vision screening needs to be provided for everyone in Romania' was a statement that $97.9 \%$ of screeners (strongly) agreed with and 95.9\% (strongly) agreed with the statement that it should be free of charge.

Vision screening was mostly considered appropriate (table 1b), although more so in the urban than the rural areas. 
In rural areas, many family doctors and their nurses lacked time to participate in screening and more parents were not cooperative, because of a lack of awareness of the benefits. In the questionnaire, $85.0 \%$ of screeners (strongly) agreed with the statement 'educational material can improve compliance'.

Screening was feasible (table 1c) in the cities because kindergartens are large and employ resident nurses. In rural areas kindergartens are small and have no resident nurses and the alternatives were not as practical, decreasing feasibility.

Adoption (table 1d) was good in the cities but not in all rural areas. Of all rural family doctors' nurses, less than half followed the screening course, of whom $58.8 \%$ went on to screen children, as compared to $70.9 \%$ of urban nurses who followed the course.

Fidelity (table 1e) was generally considered good. Screeners felt confident to perform screening adequately and the observed screenings were largely carried out according to protocol. However, two nurses, who screened more than 92 children, did not refer a single child. This is highly improbable. Another nurse, who screened 86 children in 2018, recorded the exact same visual acuity for all of them in both eyes.

Coverage (table 1f) was good in urban areas, but less so in the rural areas: in the cities $2.24 \mathrm{x}$ the average birth rate was screened and in the rural areas 1.41x.

Although all stakeholders expressed the opinion that vision screening should be continued, its sustainability (table 1g) was considered unsure because of a lack of health funding and low prioritisation of preventive healthcare. Nevertheless, some nurses who were interviewed said they will continue screening even if they no longer receive additional reimbursement for screening, because screening enhances their status in the eyes of the parents and the community.

Tables 1a-g: To evaluate the barriers and facilitators of the implementation, implementation outcomes were evaluated, using a framework based on Peters et al [17] and Proctor et al [18]. The outcome measures acceptability, feasibility, appropriateness adoption, fidelity, coverage and sustainability were assessed and are shown here in relation to the measurement methods used.

\section{Table 1a: acceptability}

\begin{tabular}{|c|c|c|}
\hline $\begin{array}{l}\text { On-site interviews and } \\
\text { focus groups with nurses, } \\
\text { interview with travelling } \\
\text { screening nurse, interviews } \\
\text { with family doctors and kin- } \\
\text { dergarten staff }\end{array}$ & $\begin{array}{l}\text { Urban \& } \\
\text { rural }\end{array}$ & $\begin{array}{l}\text { Vision screening was considered as important by the majority of nurses, } \\
\text { family doctors and kindergarten staff. }\end{array}$ \\
\hline $\begin{array}{l}\text { On-site interviews with } \\
\text { other stakeholders }\end{array}$ & $\begin{array}{l}\text { Urban \& } \\
\text { rural }\end{array}$ & All stakeholders felt screening was important. \\
\hline Questionnaires for screeners & $\begin{array}{l}\text { Urban \& } \\
\text { rural }\end{array}$ & $\begin{array}{l}\text { The majority of nurses expressed a positive attitude towards screening } \\
\text { and indicated they believe screening is important and should be pro- } \\
\text { vided to all children. }\end{array}$ \\
\hline $\begin{array}{l}\text { On-site interviews and } \\
\text { focus groups with nurses, } \\
\text { interview with travelling } \\
\text { screening nurse, interviews } \\
\text { with family doctors and kin- } \\
\text { dergarten staff }\end{array}$ & $\begin{array}{l}\text { Urban \& } \\
\text { rural }\end{array}$ & $\begin{array}{l}\text { Vision screening was considered as important by the majority of nurses, } \\
\text { family doctors and kindergarten staff. }\end{array}$ \\
\hline $\begin{array}{l}\text { On-site interviews with } \\
\text { other stakeholders }\end{array}$ & $\begin{array}{l}\text { Urban \& } \\
\text { rural }\end{array}$ & All stakeholders felt screening was important. \\
\hline Questionnaires for screeners & $\begin{array}{l}\text { Urban \& } \\
\text { rural }\end{array}$ & $\begin{array}{l}\text { The majority of nurses expressed a positive attitude towards screening } \\
\text { and indicated they believe screening is important and should be pro- } \\
\text { vided to all children. }\end{array}$ \\
\hline $\begin{array}{l}\text { Questionnaires for family } \\
\text { doctors }\end{array}$ & Rural & All rural family doctors considered vision screening important. \\
\hline
\end{tabular}




\section{Table 1b: appropriateness}

\begin{tabular}{|l|l|l|}
\hline $\begin{array}{l}\text { On-site interviews and focus } \\
\text { groups with nurses }\end{array}$ & Urban \& rural & $\begin{array}{l}\text { Most parents reacted well to the idea of vision screening, but some } \\
\text { were not interested in vision screening at all. Reports on how many } \\
\text { parents refused varied. } \\
\text { A few nurses thought four-year-olds were too young to screen prop- } \\
\text { erly. }\end{array}$ \\
\hline $\begin{array}{l}\text { On-site interviews with fam- } \\
\text { ily doctors }\end{array}$ & Rural & $\begin{array}{l}\text { Most family doctors felt they and their nurses had too much other pre- } \\
\text { ventive health care priorities to be able to screen and that parents lack } \\
\text { awareness of the benefits of preventive health care. }\end{array}$ \\
\hline $\begin{array}{l}\text { On-site interview with trav- } \\
\text { elling screening nurse }\end{array}$ & Rural & $\begin{array}{l}\text { The travelling screening nurse had little contact with parents and en- } \\
\text { countered varying degrees of cooperation by kindergarten staff. }\end{array}$ \\
\hline $\begin{array}{l}\text { On-site interviews with kin- } \\
\text { dergarten staff }\end{array}$ & Urban & $\begin{array}{l}\text { Screening by nurses in kindergartens was considered suitable for the } \\
\text { setting. Most parents reacted well to the idea of vision screening. }\end{array}$ \\
\cline { 2 - 3 } & Rural & $\begin{array}{l}\text { Opinions among kindergarten staff were divided. Some said parents } \\
\text { were positive about vision screening while others said parents were } \\
\text { negative. }\end{array}$ \\
\hline Questionnaires for screeners & Urban \& rural & $\begin{array}{l}\text { Most respondents said parents think vision screening is important and } \\
\text { are open to their children being screened. }\end{array}$ \\
\hline $\begin{array}{l}\text { Questionnaires for rural } \\
\text { family doctors }\end{array}$ & Rural & $\begin{array}{l}\text { Some family doctors said parents would be positive about vision } \\
\text { screening, others said they would not. }\end{array}$ \\
\hline
\end{tabular}

\section{Table 1c: feasibility}

\begin{tabular}{|c|c|c|}
\hline \multirow[t]{2}{*}{$\begin{array}{l}\text { On-site interviews } \\
\text { and focus groups } \\
\text { with nurses }\end{array}$} & Urban & $\begin{array}{l}\text { The kindergartens were a practical setting, because the nurses see a lot of children } \\
\text { every day and know the children and their } \\
\text { parents well. The kindergartens also have medical offices that are suitable as } \\
\text { screening space. }\end{array}$ \\
\hline & Rural & $\begin{array}{l}\text { The family doctors' offices were not a practical setting, because parents did not } \\
\text { bring their children. Some nurses did not have the time to screen. Screening in } \\
\text { rural kindergartens was hampered by low attendance and travel distances. In a few } \\
\text { kindergartens there was no suitable space to measure VA or the staff did not coop- } \\
\text { erate. }\end{array}$ \\
\hline $\begin{array}{l}\text { On-site interview } \\
\text { with travelling } \\
\text { screening nurse }\end{array}$ & Rural & $\begin{array}{l}\text { Screening was hampered by travelling distances, bad road conditions, low kinder- } \\
\text { garten attendance and, in some cases, cooperation and communication issues with } \\
\text { kindergarten staff. Lack of contact with parents made it difficult to keep track of } \\
\text { follow-up. }\end{array}$ \\
\hline $\begin{array}{l}\text { On-site interviews } \\
\text { with family doctors }\end{array}$ & Rural & $\begin{array}{l}\text { Most family doctors indicated their nurses lacked time to screen and do the paper- } \\
\text { work involved. }\end{array}$ \\
\hline \multirow{2}{*}{$\begin{array}{l}\text { On-site interviews } \\
\text { with kindergarten } \\
\text { staff }\end{array}$} & Urban & Resident nurses could screen large numbers of children. \\
\hline & Rural & $\begin{array}{l}\text { Kindergartens were considered less practical because of a lack of nurses and the } \\
\text { low numbers of children attending. Some kindergarten staff welcomed screening } \\
\text { at the kindergarten by the family doctor's nurse though. }\end{array}$ \\
\hline $\begin{array}{l}\text { Questionnaires for } \\
\text { family doctors }\end{array}$ & Rural & $\begin{array}{l}\text { Lack of funds, too many patients, personnel costs, travel time to patients in remote } \\
\text { areas would make screening difficult. }\end{array}$ \\
\hline \multirow[t]{2}{*}{$\begin{array}{l}\text { On-site observation } \\
\text { of screening }\end{array}$} & Urban & $\begin{array}{l}\text { Nurses were mostly able to carry out screening according to protocol in the kin- } \\
\text { dergartens. }\end{array}$ \\
\hline & Rural & $\begin{array}{l}\text { Nurses were mostly able to carry out screening according to protocol in family } \\
\text { doctors' offices and kindergartens. }\end{array}$ \\
\hline
\end{tabular}




\begin{tabular}{|c|c|c|}
\hline \multicolumn{3}{|c|}{ Table 1d: adoption } \\
\hline \multirow{2}{*}{$\begin{array}{l}\text { On-site interviews } \\
\text { and focus groups } \\
\text { with nurses and } \\
\text { interview with } \\
\text { travelling screen- } \\
\text { ing nurse }\end{array}$} & Urban & $\begin{array}{l}\text { Introducing vision screening was considered a good idea and nurses were enthusi- } \\
\text { astic to participate. }\end{array}$ \\
\hline & Rural & $\begin{array}{l}\text { Some nurses were enthusiastic to participate in screening, but others said they } \\
\text { lacked the time to do so, even though they felt it was important. }\end{array}$ \\
\hline $\begin{array}{l}\text { On-site interviews } \\
\text { with family doctors }\end{array}$ & Rural & $\begin{array}{l}\text { Most family doctors indicated their nurses did not have to time to take up screen- } \\
\text { ing and do the paperwork involved. }\end{array}$ \\
\hline $\begin{array}{l}\text { On-site interviews } \\
\text { with kindergarten } \\
\text { staff }\end{array}$ & $\begin{array}{l}\text { Urban \& } \\
\text { rural }\end{array}$ & Vision screening was considered a good idea and staff were inclined to cooperate. \\
\hline $\begin{array}{l}\text { Questionnaires for } \\
\text { screeners }\end{array}$ & $\begin{array}{l}\text { Urban \& } \\
\text { rural }\end{array}$ & The majority of nurses considered vision screening a natural part of their work. \\
\hline \multirow{2}{*}{$\begin{array}{l}\text { Data analysis of } \\
\text { screening results }\end{array}$} & Urban & $70.9 \%$ of the nurses who followed the course, screened children. \\
\hline & Rural & $58.8 \%$ of the nurses who followed the course, screened children. \\
\hline \multicolumn{3}{|c|}{ Table 1e: fidelity } \\
\hline $\begin{array}{l}\text { On-site interviews } \\
\text { and focus groups } \\
\text { with nurses }\end{array}$ & $\begin{array}{l}\text { Urban \& } \\
\text { rural }\end{array}$ & $\begin{array}{l}\text { Nurses said they were able to perform screening adequately, though some men- } \\
\text { tioned it was a bit difficult in the beginning. }\end{array}$ \\
\hline $\begin{array}{l}\text { On-site interview } \\
\text { with travelling } \\
\text { screening nurse }\end{array}$ & Rural & $\begin{array}{l}\text { The travelling screening nurse screened many children and felt able to perform } \\
\text { screening adequately. }\end{array}$ \\
\hline $\begin{array}{l}\text { Questionnaires for } \\
\text { screeners }\end{array}$ & $\begin{array}{l}\text { Urban \& } \\
\text { rural }\end{array}$ & Nurses felt confident they were able to adequately screen children. \\
\hline $\begin{array}{l}\text { On-site observation } \\
\text { of screening }\end{array}$ & $\begin{array}{l}\text { Urban \& } \\
\text { rural }\end{array}$ & $\begin{array}{l}\text { Nurses performed screening largely according to protocol, with few exceptions. } \\
\text { Performance of nurses had improved in } 2019 \text { as compared to } 2018 \text {. }\end{array}$ \\
\hline $\begin{array}{l}\text { Data analysis of } \\
\text { screening results }\end{array}$ & $\begin{array}{l}\text { Urban \& } \\
\text { rural }\end{array}$ & $\begin{array}{l}\text { There were many outliers among nurses when it came to referral rates - both very } \\
\text { low and very high referral rates - and also other indications that the protocol was } \\
\text { not always followed correctly. }\end{array}$ \\
\hline
\end{tabular}

Table 1f: coverage

\begin{tabular}{|c|c|c|}
\hline \multirow{2}{*}{$\begin{array}{l}\text { On-site interviews } \\
\text { and focus groups } \\
\text { with nurses }\end{array}$} & Urban & Most parents consented to having their child screened. \\
\hline & Rural & $\begin{array}{l}\text { Most parents did not bring their children to the doctor's office for screening. Most } \\
\text { family doctors' nurses who went on to screen in kindergartens said that they only } \\
\text { found small numbers of children there. }\end{array}$ \\
\hline $\begin{array}{l}\text { On-site interview } \\
\text { with travelling } \\
\text { screening nurse }\end{array}$ & Rural & Coverage was hampered by low attendance figures at the rural kindergartens. \\
\hline $\begin{array}{l}\text { Questionnaires for } \\
\text { screeners }\end{array}$ & $\begin{array}{l}\text { Urban \& } \\
\text { rural }\end{array}$ & $\begin{array}{l}\text { Opinions were divided about parents' willingness to accept vision screening and } \\
\text { compliance with referrals. }\end{array}$ \\
\hline \multirow{2}{*}{$\begin{array}{l}\text { Data analysis of } \\
\text { screening results }\end{array}$} & Urban & $74.8 \%$ of all eligible children were screened. \\
\hline & Rural & $47.1 \%$ of all eligible children were screened. \\
\hline
\end{tabular}




\begin{tabular}{|l|l|l|}
\hline \multicolumn{2}{|c|}{ Table 1g: sustainability } \\
\hline $\begin{array}{l}\text { On-site interviews } \\
\text { and focus groups } \\
\text { with nurses }\end{array}$ & $\begin{array}{l}\text { Urban \& } \\
\text { rural }\end{array}$ & $\begin{array}{l}\text { Many nurses expressed their intention to continue screening in the future, even } \\
\text { when they would not be receiving additional remuneration for doing so. }\end{array}$ \\
\hline $\begin{array}{l}\text { On-site interview } \\
\text { with travelling } \\
\text { screening nurse }\end{array}$ & Rural & $\begin{array}{l}\text { The main problem for the travelling screening nurse was that she encountered few } \\
\text { children at the rural kindergartens and that she would not know in advance how } \\
\text { many children she would screen and therefore could not count on a fixed income, } \\
\text { making the job unattractive. }\end{array}$ \\
\hline $\begin{array}{l}\text { On-site interviews } \\
\text { with family doctors }\end{array}$ & Rural & $\begin{array}{l}\text { Family doctors felt screening should be continued, but thought financing screening } \\
\text { would be a problem. Vision screening is supposed to be part of a general yearly } \\
\text { health check-up, but this is not always carried out because it is not reimbursed } \\
\text { separately. }\end{array}$ \\
\hline $\begin{array}{l}\text { On-site interviews } \\
\text { with other stake- } \\
\text { holders }\end{array}$ & $\begin{array}{l}\text { Urban \& } \\
\text { rural }\end{array}$ & $\begin{array}{l}\text { All stakeholders thought government financing for screening unlikely to happen, } \\
\text { because the health budget is low and there are many other priorities. Prevention is } \\
\text { usually not a priority and several screening programmes were discontinued after } \\
\text { pilots were considered unsuccessful. And even if screening were financed, financ- } \\
\text { ing follow-up would be a problem. }\end{array}$ \\
\hline $\begin{array}{l}\text { Questionnaires for } \\
\text { screeners }\end{array}$ & $\begin{array}{l}\text { Urban \& } \\
\text { rural }\end{array}$ & $\begin{array}{l}\text { The vast majority of respondents felt vision screening should be offered to all chil- } \\
\text { dren in Romania, free of charge. }\end{array}$ \\
\hline
\end{tabular}

\section{DISCUSSION}

In the cities, three-quarters of eligible four- or five-year-old children were screened in 2018 and 2019. Key to substantial coverage was for screeners to have access to large numbers of children at the same place and time. The resident nurses in the large kindergartens in cities had this access and, in addition, the children already knew and trusted them and they already had a relationship with the parents as well. The fact they received reimbursement per child screened, in addition to their salary, which would not be the case in a regular screening programme, may have been an additional motivating factor for the nurses.

In rural areas coverage was initially low. Few family doctors' nurses even attempted to screen children, with many citing lack of time and too many other healthcare priorities as reasons. In the urban areas there is one family doctor per 1,559 inhabitants as compared to one per 2,372 in rural areas. In two rural communes in Cluj, there is no family doctor at all [5]. In the whole of Romania, $5 \%$ of rural communities have no doctor and less than $20 \%$ of doctors work in rural areas and [21].

Most family doctors' nurses who screened children, reported that parents often did not bring their children to the doctor's office when invited specifically for screening. While it can be considered this was due to a lack of health awareness, it should also be noted that for one-third of the rural population, a visit to a doctor's office requires between 30 and 60 minutes of travel one-way or even more [22].

Family doctors' nurses who proceeded to screen at kindergartens instead, reported they found fewer children there than expected. This low kindergarten attendance was explained by parents taking their children to kindergartens in cities when they work there and by many parents going abroad to work.

The employment of a travelling screening nurse in 2019, who screened children at rural kindergartens in communes where children were not screened by a family doctor's nurse, substantially increased coverage in rural areas. The travelling screening nurse caused the number of communes where children were screened to increase from $32 \%$ after one year to $96 \%$ after two years.

The travelling screening nurse provided a solution for areas where no screening would take place otherwise. At the end of the implementation, coverage in rural areas was still considerably lower than in urban areas but it is likely that coverage would have been higher if a travelling screening nurse had been employed from the start of the implementation. 
Considering that screening by family doctors or their nurses is currently not feasible in many rural communes, the employment of a travelling nurse as a dedicated screener is necessary to ensure rural coverage when vision screening by measurement of visual acuity at age four or five becomes universal in all of Romania. It should be noted, though, that the disadvantages of the job noted by the travelling screening nurse should be addressed, such as the lack of a stable income and the need to use a personal car.

In addition to screening itself, the travelling screening nurse could provide instruction on vision screening to family doctors and their nurses. For nationwide implementation of vision screening, it seems advisable to appoint one travelling screening nurse in every county, in some counties maybe more.

Measurement of visual acuity according to the new protocol does take some time, but only has to be done at age four or five. Currently, family doctors in Romania may screen for vision disorders at ages two to seventeen [3].

The new protocol for visual acuity measurement proved effective and screening was mostly performed according to the protocol. Some nurses, though, referred no children even when screening large numbers of children which cannot be explained with the prevalence of amblyopia of $3.4 \%$. Adequate supervision, monitoring, audit and re-training of screeners are needed to ensure quality.

Of the 1,505 children were referred, approximately two-fifths had been examined, but approximately one-fifth definitely not and the remainder was unknown. In rural areas, lack of local ophthalmologists and travel costs to cities were significant barriers to follow-up. Parents in rural areas have less resources than parents in urban areas: the average total income per person in Romania in 2018 in rural areas was $62.2 \%$ of the average income in urban areas [5]. The health insurance covers the costs of a visit to an ophthalmologist and treatment of amblyopia, but not the costs of glasses or eye patches in children with amblyopia [23].

Parental awareness and attitudes towards vision and eye care, such as low prioritisation and not believing their child needs glasses, also play an important role in the uptake of vision screening and follow-up attendance [24]. This is especially so in the rural areas where health literacy is low [25]. This should be addressed with better educational information for parents.

Most of the children examined by ophthalmologists, had been prescribed glasses. Occlusion therapy was prescribed only in a minority of cases. Occlusion therapy is time-consuming because it requires frequent check-ups, every 6-12 weeks [26]. Unlike in most other European countries, there are no orthoptists in Romania yet. Universal vision screening at age four or five in Romania will result in many children with amblyopia needing treatment with glasses and eye patches. Apart from reimbursement of glasses and eye patches in children with amblyopia, a training programme for orthoptists would be advisable. Orthoptists could provide expert amblyopia diagnosis and treatment, assisting ophthalmologists in all cities in Romania. Treatment could be offered to all children detected by vision screening nearby, both in urban and rural areas.

\section{CONCLUSIONS}

In cities in Cluj County, vision screening by measurement of visual acuity at age four or five, performed by resident kindergarten nurses, proved very effective. The nurses had access to many children who knew and trusted them.

In rural areas, family doctors' nurses could screen only small numbers of children and, initially, in many rural communes no screening took place. A travelling screening nurse was employed, who screened many children in these underserved communes and screening had been offered to children in almost all rural communes at the end of the study.

The new protocol for measurement of visual acuity at age four and five proved effective, and screening was mostly performed according to the protocol.

Training of screeners, supervision and monitoring proved to be important to ensure quality. Universal vision screening at age four or five in Romania will result in many children with amblyopia needing treatment with glasses and eye patches. Reimbursement of these by health insurance and a training programme for orthoptists could be considered. 


\section{REFERENCES}

1. Euscreen website. https://www.euscreen.org. Accessed 11 August 2021.

2. Euscreen cost-effectiveness model. https://miscan.euscreen.org. Accessed 20 October 2021.

3. Norme Metodologice din 29 iunie 2021. https://legislatie.just.ro/Public/DetaliiDocument/244628. Accessed 25 October 2021.

4. Kik J, Nordmann M, Cainap S, Mara M, Rajka D, Ghitiu M, Vladescu A, Sloot F, Horwood AM, Fronius M, Vladutiu C, Simonsz HJ. Implementation of paediatric vision screening in urban and rural areas in Cluj County, Romania. Int J Equity Health [in press].

5. Romanian National Institute for Statistics. http://statistici.insse.ro:8077/tempo-online/\#/pages/tables/insse-table. Accessed 2 April 2019.

6. Groenewoud JH, Tjiam AM, Lantau VK et al, Hoogeveen WC, Tjeerd J, Faber HN de, Juttmann RE, Koning HJ de, Simonsz HJ. Rotterdam AMblyopia Screening Effectiveness Study: Detection and Causes of Amblyopia in a Large Birth Cohort. IOVS. 2010;51:3476-3484.

7. Fronius M. Okklusionstherapie bei Amblyopie. Altersabhängigkeit und Dosis-Wirkungs-Beziehung. Ophthalmologe 2016;113:296-303.

8. Holmes J, Levi D. Treatment of amblyopia as a function of age. Vis Neurosci. 2018;35:E015.

9. Høeg TB, Moldow B, Ellervik C, Klemp K, Erngaard D, Cour M la, Buch H. Danish Rural Eye Study: the association of preschool vision screening with the prevalence of amblyopia. Acta Ophthalmol. 2015;93:322-329.

10. Telleman MAJ, Sloot F, Benjamins J, Simonsz HJ. High rate of failed visual-acuity measurements with the Amsterdam Picture Chart in screening at the age of 36 months. Acta Ophthalmol. 2019;97(1):24-28.

11. International Organization for Standardization, Ophthalmic optics - Visual acuity testing - Standard and clinical optotypes and their presentation (ISO Standard No. 8596:2017).

12. Ordin nr. 141 din 1 martie 2000. http://legislatie. just.ro/Public/DetaliiDocumentAfis/23814. Accessed 24 August 2021.

13. Ciolan L, Iucu R, Petrescu A, Bucur C. Romania ECEC Workforce Profile. In: Oberhuemer P, Schreyer I, editors. Early Childhood Workforce Profiles in 30 Countries with Key Contextual Data. 2018;Munich: SEEPRO-R:930-954.

14. Hotărârea nr. 714/2018 din 13 septembrie 2018. https://codfiscal.net/46238/hg-714-2018-indemnizatia-de-deplasare-detasare-alocatia-de-cazare-drepturi-si-obligatii-personal-bugetar. Accessed 20 October 2021.

15. Ursuletul la Oftalmolog v 2.0. https://www.youtube. com/watch? $\mathrm{v}=$ GrecUmlUXV8. Accessed 1 October 2021.

16. WMA. https://www.wma.net/policies-post/wma-declaration-of-helsinki-ethical-principles-for-medical-research-involving-human-subjects. Accessed 21 November 2019.

17. Peters DH, Adam T, Alonge O, Agyepong IA, Tran N. Implementation research: what it is and how to do it. BMJ. 2013;347:f6753.
18. Proctor E, Silmere H, Raghavan R, Hovmand P, Aarons G, Bunger A, Griffey R, Hensley M. Outcomes for Implementation Research: Conceptual Distinctions, Measurement Challenges, and Research Agenda. Adm Policy Ment Health. 2011;38(2):65-76.

19. Leech B. Asking Questions: Techniques for Semistructured Interviews. PS. 2002;35(4):665-668.

20. Thomas DR. A General Inductive Approach for Analyzing Qualitative Evaluation Data. Am J Eval. 2006;27(2):237-246.

21. Dumitrache L, Nae M, Dumbrăveanu D, Simion G \& Suditu B. Contrasting Clustering in Health Care Provision in Romania: Spatial and Aspatial Limitations. Procedia Environmental Sciences. 2016;32: 290-299.

22. World Health Organization. Evaluation of the organization and provision of primary care in Romania. A survey-based project. 2012; Copenhagen: WHO Regional Office for Europe.

23. Predescu M. Quality in and Equality of Access to Healthcare Services. Country Report for Romania. 2008;Bucharest: The Institute of Public Health.

24. Vongsachang H, Friedman D, Inns A, Kretz A, Mukherjee M, Callan J, Wahl M, Repka M, Collins M. Parent and Teacher Perspectives on Factors Decreasing Participation in School-Based Vision Programs. Ophthalmic Epidemiol. 2020;27:1-11.

25. Pop OM, Brînzaniuc A, Şirlincan EO, Baba CO, Cherecheş RM. Assessing health literacy in rural settings: a pilot study in rural areas of Cluj County, Romania. Glob Health Promot. 2013;20(4):35-43.

26. Holmes JM, Clarke MP. Amblyopia. The Lancet. 2006;367(9519):1343-1351.

\section{Declarations \\ Acknowledgements}

Good-Lite (Elgin, IL, USA) donated the eye charts used for visual acuity measurement.

\section{Consent for publication}

Not applicable.

\section{Availability of data and materials}

The datasets generated and analysed during the current study are not publicly available due to privacy considerations.

\section{Competing interests}

The authors have no competing interests relevant to this article to disclose.

\section{Funding}

This study has received funding from the European Union's Horizon 2020 research and innovation programme under grant agreement No 733352. 
The study sponsor had no role in the study design, or the collection, analysis and interpretation of the data or in the writing of the report or in the decision to submit the article for publication.

\section{Authors' contributions}

JK carried out the implementation study, drafted the initial manuscript, collected data, carried out the data analyses, reviewed and revised the manuscript and approved the final manuscript as submitted.

MN carried out the implementation study, collected data, carried out the data analyses, reviewed and revised the manuscript and approved the final manuscript as submitted.

DR conceptualised and designed the implementation, implemented the screening programme in Romania, reviewed the manuscript and approved the final manuscript as submitted.

MM implemented the screening programme in Romania, collected data, reviewed the manuscript and approved the final manuscript as submitted.

SC implemented the screening programme in Romania, collected data, reviewed the manuscript and approved the final manuscript as submitted.

OT implemented the screening programme in Romania, collected data, reviewed the manuscript and approved the final manuscript as submitted.

AV implemented the screening programme in Romania, collected data, reviewed the manuscript and approved the final manuscript as submitted.
AM implemented the screening programme in Romania, reviewed the manuscript and approved the final manuscript as submitted.

AH observed the implementation study, participated in the training courses for screeners, critically reviewed and revised the manuscript and approved the final manuscript as submitted.

MF observed the implementation study, participated in the training courses for screeners, critically reviewed and revised the manuscript and approved the final manuscript as submitted.

$\mathrm{CV}$ conceptualised and designed the implementation, implemented the screening programme in Romania, reviewed the manuscript and approved the final manuscript as submitted.

HJS conceptualised and designed the implementation study, drafted the initial manuscript, carried out the data analyses, critically reviewed and revised the manuscript and approved the final manuscript as submitted.

Additional file 1:

\section{Cluj County and Romanian healthcare}

\section{Cluj County}

The county of Cluj in north-western Romania had a population of 730,216 in 2018 [1].

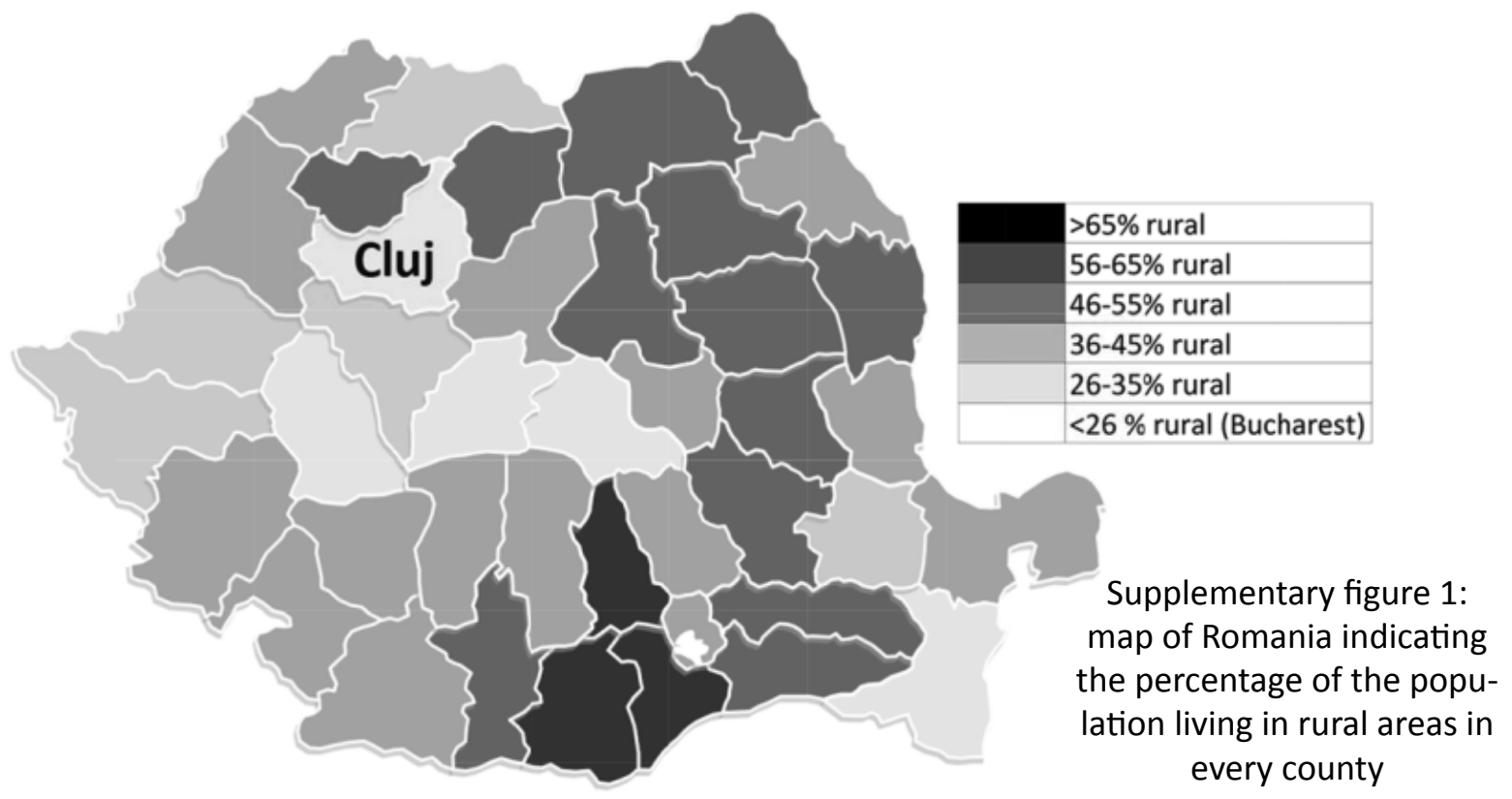


The city of Cluj-Napoca is the county seat with a population of 324,276 . There are five small cities: the municipalities of Turda (population 55,907), Dej $(38,250)$, Câmpia Turzii $(27,745)$, Gherla $(23,002)$ and the town of Huedin $(9,564)$. In the county's rural areas 251,481 people or $34 \%$ of the population reside, spread across 75 communes (groups of villages). In the whole of Romania, $46 \%$ of the population lives in rural areas (Supplementary figure 1).

There are many differences between the rural communes: some communes are rural in name but are, in reality, more like suburbs. Florești for example, neighbouring Cluj-Napoca, has more inhabitants than most of the small cities. Other communes are indeed located remotely and inhabited by small populations spread over a relatively large area.

Population density in the communes varies from 6 per square kilometre (Belis, Valea Ierii) to 599 (Floresti). The average population density in the 75 communes is 49 per square kilometre.

\section{Romanian healthcare}

Until 1989, Romania had a healthcare system based on the Semashko model introduced in the Soviet Union in 1930 and later adopted by other communist states, characterised by state monopoly, central planning, rigid management, universal coverage and free services. However, because healthcare was considered unproductive (costing money rather than generating revenue) it was chronically underfunded during the Ceaușescu regime, with health spending being even much lower than in other Eastern bloc countries [2]. Healthcare was inefficient and not responsive to patients' needs [3].

By 1998 the system had been transformed into a social health insurance system, funded by employers and employees [4]. In 2006 national legislation was brought in line with EU law in anticipation of EU membership in 2007 [5]. This health reform law no. $95 / 2006$ is still in place, even though it has been amended many times, mainly through secondary legislation, limiting the effectiveness of health reforms [6]. Health spending in Romania is the lowest in the EU, both per capita ( $€ 1,029$ as compared to an EU average of $€ 2,884$ in 2017) and as a proportion of the GDP $(5.2 \%$ as compared to an EU average of $9.8 \%$ in 2017) [7].
There are also differences in health and healthcare between urban and rural areas. In Cluj County, mortality rate in 2018 was 10.4 in urban areas as compared to 13.9 in rural areas and life expectancy 78.5 as compared to 75.6 [1]. In the whole of Romania, health insurance coverage in 2014 was $94.9 \%$ in urban areas as compared to $75.8 \%$ in rural areas [8]. In 2018 there was one family doctor per 1,559 urban inhabitants against one per 2,372 rural inhabitants in Cluj County, one hospital bed per 74 urban inhabitants against one per 568 rural inhabitants, one pharmacy per 1,995 urban inhabitants against one per 2,620 rural inhabitants and one dentist per 563 urban inhabitants against one per 2,395 rural inhabitants [1].

\section{References}

1. Romanian National Institute for Statistics. http://statistici.insse.ro:8077/tempo-online/\#/pages/tables/insse-table. Accessed 2 April 2019 and 22 March 2021.

2. Bara AC, Heuvel WJA van den, Maarse JAM. Reforms of Health Care System in Romania. Croat Med J. 2002;43(4):446-452.

3. Spiru L, Traşcu RI, Turcu I, Mărzan M. Perpetual transitions in Romanian healthcare. EPMA J. 2011;2(4):341-350.

4. Vladescu C, Scîntee G, Olsavszky V, Allin S, Mladovsky P. Romania: Health system review. Health Systems in Transition 2008;10(3):1-172.

5. Vladescu C, Galan A, Olsavszky V, Scîntee SG. Romanian health system strategic directions for the next decade. Ital J Public Health 2009;7(6).

6. Popescu LG. Analysis of National Health Strategy 2014-2020. Theoretical and Applied Economics Volume XXII 2015;4(605):177-188.

7. OECD/European Observatory on Health Systems and Policies. Romania: Country Health Profile 2019, State of Health in the EU. OECD Publishing, European Observatory on Health Systems and Policies: Paris, Brussels; 2019.

8. Vlãdescu C, Scîntee SG, Olsavszky V, HernándezQuevedo C, Sagan A. Romania: Health system review. Health Systems in Transition 2016;18(4):1-170.

\section{Additional file 2: \\ protocol for measurement of visual acuity, screening protocol and database}

A protocol was developed based on literature and expert opinion. Based on the European standard for visual acuity measurement ISO 8596:2017 and expert opinion it was decided to use an optotype chart with logarithmic proportion and a $\log$ MAR scale, with positioning of the optotypes as in the ETDRS 
chart. Tumbling E and Lea Symbols were chosen as optotypes. The use of photoscreening was not considered as there is insufficient evidence that photoscreening is cost-effective, because of poor testability, low positive predictive value and high referral rates [1].

Approximately 200 visual acuity (VA) charts were donated by Good-Lite (Elgin, IL, USA), designed for use at three metres, with Tumbling E's on one side and LEA Symbols on the other side. VA measurement at three metres was considered an appropriate distance for young children. VA was measured in accordance with the aforementioned standard: a line on the chart ( 0.1 log spacing) is passed when a child indicates three out of five symbols correctly.

VA measurement was done by matching symbols. After the text was explained to the child, the screener put on open spectacles with one eye covered to measure VA of the other eye, with the right eye first. Screeners started using the side of the chart with Tumbling E's and if the child did not understand the test, they turned the chart to measure VA with Lea Symbols.

The threshold was defined as follows: children aged four passed the test when VA in both eyes separately was $0.2 \log$ MAR (decimal: 0.63 ) or better, with one line $(0.1 \mathrm{log})$ or less difference between the eyes. Children aged five passed the test when VA in both eyes separately was $0.1 \log$ MAR (decimal: 0.8 ) or better, with one line or less difference.

Children who did not pass the test were to be referred or to be tested again after one month, the latter when, for example, it was suspected they failed the test because they did not pay attention and not because of actually low VA. When they did not pass the second test, the screeners instructed the parents to take the children to their family doctor for referral to an ophthalmologist and gave the parents a list of ophthalmologists who had declared to be willing to examine children.

Screeners were provided with packages containing the following items:

- an instruction movie explaining how to measure VA

- an animated instruction movie for the children that the screeners could show before the actual screening took place

- informed consent forms for the parents to sign
- an optotype chart to measure VA

- registration forms to record the results of the examination

- two pairs of examination glasses for the children to wear during screening; one with the right glass covered and one with the left glass covered

- reward stickers for the children to receive after the screening

- a list of ophthalmologists

- referral forms to be filled out by the screener that parents needed to take to the family doctor for referral to an ophthalmologist

To monitor all screening results and follow-up activity of the children that were screened, an electronic database was developed. All stages of the process were to be registered as well as the results of the ophthalmological examination, if the child was referred. In addition, information like birth weight, pregnancy duration, Apgar scores and relevant medical family history was registered, if parents could provide that.

The screening nurses filled out paper forms, because not all were familiar with computers and sometimes local internet access was limited. The forms were entered in the database by the DASM or the UMF-Cluj. Once data were entered in the database, these could not be altered anymore. Instead, an additional record had to be created.

All data were processed in accordance with EU regulation 2016/679: each child was assigned an anonymous code and all personally identifying information (including place of residence) was omitted. The screeners kept separate lists, not accessible to anyone else, to be able to match the children to their codes, in case the results of a repeat screening or diagnostic assessment had to be added to the child's record in the database. These lists could also be used to eventually check why referred children's reports of ophthalmological examinations had not been returned.

All screening and examination data collected in 2018 and 2019 were exported from the electronic database on October 17, 2020 for analysis. Most data were entered correctly in the database, with the exception of some errors. A few times secretaries who entered data in the database reported having made an error in data entry, that however could not be corrected 
because the database did not allow altering recorded data. In addition to these self-reported mistakes, there were minor errors such as typos and errors that were obvious because of their internal inconsistency, such as records where the child was, according to the database, not referred but a report of an ophthalmological examination was entered nevertheless, or where the first examination was entered as passed but still a second examination was entered.

While it is not possible to say exactly how many errors were made, based on the available information it is estimated less than $1 \%$ of database records were affected by errors.

The fact that first paper forms were filled out by the nurses that were subsequently entered in the database by secretaries, increased the possibility of errors being made. Several interviewed nurses said they would prefer to enter the data themselves, preferably by using a smartphone app, but most of the nurses who attended the courses indicated at the time that they would prefer not to access the database themselves.

\section{Reference}

1. Rostamzad P, Horwood AM, Schalij-Delfos NE, Boelaert K, Koning HJ de, Simonsz HJ. Plusoptix photoscreener use for paediatric vision screening in Flanders and Iran. Acta Ophthalmol. 2019;98(1): 80-88.

\section{Additional file 3: protocol for measurement of visual acuity in children by family doctors and nurses}

\section{Introduction}

Correct measurement of visual acuity involves two essential elements: well-trained staff to measure visual acuity correctly and a chart that provides an accurate assessment of visual performance. Both elements have been clarified during the implementation study in Cluj. A protocol for measuring visual acuity has been made, to assist in early detection of vision disorders in children.

The optimal age for examining the child is between 4 and 6 years. At this age the child is old enough to understand and indicate the tests presented, and is young enough for the treatment to be effective.

\section{The test}

The test recommended by the EUSCREEN Study should be used in as many offices as possible. It uses the 'E' symbols and, on the back of the chart, the LEA Symbols for children who do not understand the 'E' symbols. A logarithmic chart will be used, with every following line being $80 \%$ in size of the previous line.

The lines on the chart measure visual acuity $0.1,0.125,0.16,0.2,0.25,0.32,0.4,0.5,0.63,0.8$, 1.0 (decimal values). Visual acuity 1.0 is what most adults with good vision have. These values are at the end of each row of the chart and should be used in all communications.

\section{The examination distance}

The distance between the child and the chart depends on the chart used. The distance of 3 metres is the most suitable for the collaboration capacity of children aged 4 and 5 . The chart does not require additional lighting as long as the cabinet is well-illuminated. A practice of an ophthalmologist is too dark and some practices of family doctors may also have insufficient lighting.

\section{Examination preparation}

It is advisable to put images of the LEA Symbols and of the 'E' symbols in the envelope of the letter inviting the parents for the screening so that they can practice with their child beforehand at home. This reduces the number of failed measurements. If a child is 
already wearing glasses, keep the glasses on. It is important for the little patient to fully understand what is being asked of him. Therefore explain, patiently and understandably, on a card on which a single ' $E$ ' symbol is printed, how to indicate its position. The understanding will be verified be verified with both eyes open at a distance less than the examination (for example $40 \mathrm{~cm}$ ). The child can sit on the chair or the lap of the accompanying parent or alone. The child should not sit bent forward during the examination.

\section{Measurement of visual acuity}

The examination is done with one of the eyes covered. For this, either use two pairs of glasses, each with one eye occluded, or cover one eye with a piece of paper or plastic. It is not advisable to cover the eye with the palm because the child may cheat by looking between the fingers. Usually the examination is started with the right eye, but in cases where a weaker eye is suspected, or an eye that has not reached normal visual acuity is re-examined, the examination is started with the problematic eye.

Examination starts with the symbols on the top line and gradually progresses towards the lines below, as long as the child keeps identifying at least 3 out of 5 symbols on each line correctly. When the child cannot correctly identify 3 out of 5 symbols on a particular line, the visual acuity is equal to the line above this line.

The symbols are indicated by a pencil, or other suitable instrument, which is placed under the symbol shown. The symbol can be surrounded once, to better direct the child's attention without intersecting the adjacent symbols. The child should answer within 10 seconds.

If the child does not understand the 'E' symbols, the LEA Symbols should be used (on the back of the ' $E$ ' chart). Testing is interpreted according to age and the test used. The test is 'passed' if the 4-yearold sees at least 0.63 , and the 5 -year-old at least 0.8 . A difference in visual acuity between the eyes equal to or greater than two lines is also typical for a lazy eye.

If the child does not pass the test, the child should be re-examined after four to six weeks. If the child does not pass the second test either, the child should be referred to an ophthalmologist for an examination.

\section{Notation}

Indicate which chart is used: 'E' symbols or LEA Symbols. Record the measured visual acuity as decimal value per eye. 